https://doi.org/10.15407/dopovidi2021.05.025

УДК 532.54:678.027.3.002.5

А.Ф. Булат ${ }^{\mathbf{1}}$, https://orcid.org/0000-0002-6541-2140

B.I. Слicєєв ${ }^{1}$, https://orcid.org/0000-0003-4999-8142

С.В. Семененко ${ }^{1}$, https://orcid.org/0000-0001-8707-3648

М.М. Стадничук ${ }^{1}$, https://orcid.org/0000-0002-2990-9635

Б.О. Блюсс ${ }^{2}$, https://orcid.org/0000-0003-3077-1220

${ }^{1}$ Інститут геотехнічної механіки ім. М.С. Полякова НАН України, Дніпро

2 Придніпровський науковий центр НАН України та МОН України, Дніпро

E-mail: office.igtm@nas.gov.ua, VIYelisieiev@nas.gov.ua,

evs_post@meta.ua,bblyuss@gmail.com

\title{
Течія неньютонівської рідини в екструзійному апараті для тривимірного друку
}

Представлено академіком НАН Украӥни А.Ф. Булатом

Математичні моделі екструдування показують, що під час течії високов'язких рідин в процесі тривимірного друкування виникає проблема нагріву робочого середовища. Вона полягає в тому, що під час подачі матеріалу включається механізм дисипації механічної енергї в теплову, що зумовлює перегрів рідини. У свою чергу це може призводити до невідповідності форм одержуваного виробу. Для стійкого формування необхідно, щоб матеріал, що подається, оплавлявся біля стінок апарата. Перегрів має бути мінімальним, щоб, виходячи з насадка, матеріал міг швидко застигнути, бажано без додаткових обдувних пристроїв. У цій статті розглядається задача про рух полімерної маси в каналі з підігрівом з метою визначення необхідних умов виконання такої операції, виходячи з певних геометричних форм екструдера. Як модельна рідина використовується непружне середовище із в'язкістю, що залежить від температури та градієнтів швидкостей. Це досить широко використовуваний у практичних розрахунках клас неньютонівських модельних рідин для визначення параметрів течї полімерів і передбачення певних властивостей одержуваних виробів. Нехтування пружними властивостями полімерів часто є виправданим у зв'язку з незначністю проявів цих властивостей або з чіткою локалізацією цих ефектів. Для розв'язання задачі, сформульованої в рамках теорії вузького каналу, використовується метод смуг, в межах яких температура приймається постійною, тобто незалежною від поперечної координати. Це дає можливість покласти в основу розв'язання відомі аналітичні вирази для швидкостей з подальшим уточненням $і x, y$ зв'язку зі складною залежністю в'язкості від градієнтів швидкості. Уточнюючи на кожному кроці динамічні параметри течї з попереднвого кроку, можна чисельно отримати досить стійкі гладкі розв'язки. Розрахунки були проведені для неньютонівської рідини, близької за своїми властивостями до полімеру АБС-ЗА. Розрахунки показали, що властивість псевдопластичності, яка притаманна цьому полімеру, відіграє важливу роль у процесі екстру-

Ци т у в анн я: Булат А.Ф., Єлісєєв В.І., Семененко Є.В., Стадничук М.М., Блюсс Б.О. Течія неньютонівської рідини в екструзійному апараті для тривимірного друку. Допов. Наи. акад. наук Укр. 2021. № 5. C. 25-32. https://doi.org/10.15407/dopovidi2021.05.025 
дування. Завдяки тому, що зі збільшенням поперечного градієнта поздовжньої швидкості в'язкість иього полімеру значно падає, величина дисипачії механічної енергї теж падає, тобто зменшується теплова енергія, що виділяється під час дисипащії. Це в свою чергу призводить до меншого нагрівання полімерного матеріалу, що рухається. Отже, виходячи з геометричних розмірів апарата, можна моделювати течію полімерної рідини та підбирати параметри формування і температури рідини на виході з апарата.

Ключові слова: неньютонівські рідини, полімери, в’язкість, температура, екструзійний апарат.

Клас неньютонівських рідин дуже широкий. До нього входять різні середовища, які мають деякий ступінь пружності, їхня внутрішня енергія може залежати від деформацій; а рівняння стану містить незалежні кінематичні параметри [1]. У практичній площині врахування реологічних особливостей матеріалу часто зводиться до рівняння, яке зв'язує в'язкість з градієнтами швидкостей [2]. При розгляді течій у вузьких шарах або відносно довгих трубках можна обмежитися залежністю в'язкості від градієнтів поздовжньої швидкості за радіусом $\gamma=\partial u / \partial r$, що й наводиться в довідниках (див. наприклад, [3]). Такі залежності зручні для аналізу течій з урахуванням теплообмінних процесів, зокрема, для моделювання течій в екструдері для тривимірного друкування. У роботах [4-7] показано, що використання полімерів, близьких за своїми фізичними властивостями до ньютонівських рідин типу поліетилентерефталату (ПЕТФ), наштовхується на проблему, пов'язану з дисипацією механічної енергії. Висока динамічна в'язкість викликає дисипації механічної енергії, яка в свою чергу призводить до перегріву матеріалу навіть за порівняно невеликих швидкостей подачі. У класі неньютонівських рідин є полімери типу АБС, для яких властиве значне зниження динамічної в'язкості з ростом $(\gamma)$. АБС-пластик - це сополімер трьох основних мономерів, які використовуються в різних часткових поєднаннях та зумовлюють певний інтервал зміни основних фізичних характеристик [8]. У роботі, що пропонується, як модельну рідину розглянемо полімер, близький за своїми властивостями до цього матеріалу, для чого скористаємося порівняно простою залежністю в'язкості виду

$$
\mu=\frac{\mu_{0}}{(1+\alpha \gamma)^{m}} \exp \left(\frac{A}{T}\right)
$$

і використаємо дані з [3] для АБС-3А полімеру у формі виписаної залежності. Ця форма запису не дозволяє з високим ступенем точності апроксимувати наведені дані у всьому діапазоні зміни $\gamma$, але в межах розкиду теплофізичних характеристик цього полімеру дозволяе цілком чітко та просто оцінити вплив псевдопластичності (тобто падіння в'язкості), а отже і вплив дисипації на рух і теплообмін у цьому випадку.

Математична постановка задачі та іiі розв'язання. Як і в [4-7], беручи до уваги, що течія відбувається в порівняно вузьких каналах, випишемо основні рівняння руху та теплообміну, наведені в $[9,10]$, у спрощеній формі, яка враховує, що поперечні градієнти є значно більшими за поздовжні, тобто в рамках теорії примежового шару

$$
\begin{aligned}
& 0=-\frac{d p}{d x}+\rho g+\frac{\partial}{r \partial r}\left(\mu \frac{r \partial u}{\partial r}\right), \\
& \frac{\partial r u}{\partial x}+\frac{\partial r v}{\partial r}=0,
\end{aligned}
$$




$$
\rho c\left(u \frac{\partial T}{\partial x}+v \frac{\partial T}{\partial r}\right)=\frac{\partial}{r \partial r}\left(r \frac{\partial q}{\partial r}\right)+\mu\left(\frac{\partial u}{\partial r}\right)^{2},
$$

де $x, r$ - циліндрична система координат; $\rho$ - густина, кг $/ \mathrm{m}^{3} ; u, v-$ швидкості, відповідно поздовжня та поперечна, м/c; $p$ - тиск, Н/м²; $T$ - температура, К; $c-$ коефіцієнт тепло-

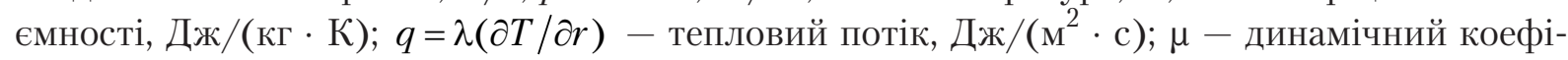
цієнт в’язкості, Па · с; $\lambda$ - коефіцієнт теплопровідності, Дж/(м · $\cdot$ К).

Перше рівняння (2) у виписаній системі є рівнянням руху без лівої конвективної частини (в подібних завданнях динамічні члени вважаються малими в порівнянні з в’язкими). Друге рівняння - це рівняння нерозривності і третє (4) - рівняння теплообміну 3 дисипативним членом. Розділивши радіус каналу $(R)$ на $N$ смуг (першою смугою вважатимемо прилеглу до осі каналу), приймемо також, що в кожній смузі температура рідини є постійною. Для випадку ньютонівської рідини це полегшує розв’язання завдяки тому, що рівняння (2) у смузі легко інтегрується і швидкість може бути записана у вигляді

$$
u_{j}=\frac{R^{2}}{4 \mu_{j}}\left(\frac{\partial p}{\partial z}-p g\right) n^{2}+a_{j} \ln n+b_{j}
$$

де $n=r / R ; a_{\mathrm{j}} \mathrm{i} b_{\mathrm{j}}-$ сталі інтегрування, $j-$ номер смуги.

Для неньютонівської рідини з формулою (1) аналітичний вираз для швидкості можна отримати лише для окремих значень показника $m$, що ускладнює розв’язок. Тому далі приймемо, що величина $\mu_{\mathrm{j}}$ у смузі також є постійною, але їі значення будемо коригувати за розрахунками на попередньому кроці. Отже, залежність для швидкості залишається у вигляді формули (5). Будемо розглядати випадок, коли температура стінки каналу є постійною та незначно перевищує температуру плавлення полімеру. Далі вважаємо, що до точки плавлення (за точку плавлення приймемо точку, в якій відповідно до нашої умови щодо в’язкості середня температура рідини в смузі, що прилягає до стінки, стає рівною температурі стінки) швидкість стрижня є постійною й дорівнює деякій початковій швидкості $U_{\mathrm{C}}$, тобто у виразі (5) два перших члени дорівнюють нулю, а $b_{\mathrm{j}}=U_{\mathrm{C}}$. Після точки плавлення приймаємо: швидкість на стінках каналу дорівнює нулю; на межах смуг виконуються умови рівності швидкостей $u_{\mathrm{gj}}$ і дотичних напружень; на осі трубки виконується умова симетрії, тобто напруження тертя дорівнює нулю. 3 цих умов маємо

$$
a_{j}=0, b_{N}=-\frac{R^{2}}{4 \mu_{N}}\left(\frac{\partial p}{\partial z}-\rho g\right) \text { та } b_{j-1}=b_{j}+\frac{R^{2}}{4}\left(\frac{\partial p}{\partial z}-\rho g\right)\left(\mu_{j}^{-1}-\mu_{j-1}^{-1}\right) n_{j-1}^{2} .
$$

Тепер за допомогою формули (5) можна знайти середню швидкість у смузі $U_{\mathrm{J}}$ та об’ємну витрату рідини

$$
Q_{j}=\frac{1}{2}\left(n_{j}^{2}-n_{j-1}^{2}\right) R^{2} U_{J}=R^{2}\left[\frac{R^{2}}{16 \mu_{j}}\left(\frac{\partial p}{\partial z}-\rho g\right)\left(n_{j}^{4}-n_{j-1}^{4}\right)+b_{j} \frac{1}{2}\left(n_{j}^{2}-n_{j-1}^{2}\right)\right] .
$$

3 урахуванням того, що маса рідини в каналі має залишатися постійною, необхідно виконати умову 


$$
Q=\frac{1}{2} R^{2} U_{C}=\sum_{j=1}^{N} Q_{j}
$$

яка слугує для визначення градієнта тиску вздовж осі каналу. Після знаходження $\left(\frac{\partial p}{\partial z}-\rho g\right)$ з рівності (8) визначають значення швидкостей $u_{\mathrm{j}}$ и $u_{\mathrm{g} \text {. }}$ Далі як $\gamma$ для уточнення в’язкості у виразі (1) використовуємо осереднену величину, тобто

$$
\gamma_{j}=\frac{u_{g j}-u_{g j-1}}{R\left(n_{j}-n_{j-1}\right)}
$$

З урахуванням того, що теплофізичні параметри в задачі є постійними, розв'язання теплової задачі проведемо, як і в [4-7]. Інтегруючи рівняння (2) і (3) за радіусом у смузі, отримаємо такі вирази:

$$
\begin{aligned}
& \frac{d}{d x} R^{2} \int_{n_{j-1}}^{n_{j}} n u d n+R\left(n_{j} v_{j}-n_{j-1} v_{j-1}\right)-\left(n_{j} u_{g j}-n_{j-1} u_{g j-1}\right) \frac{d R}{d x}=0 \\
& p c\left(\frac{d}{d x} R^{2} \int_{n_{j-1}}^{n_{j}} n u T d n+R\left(n_{j} v_{j} T_{j}-n_{j}-n_{j-1} v_{j-1} T_{j-1}\right)\right)= \\
& =R\left(n_{j} q_{j}-n_{j-1} q_{j-1}\right)+\frac{R^{4}}{16 \mu_{j}}\left(\frac{\partial p}{\partial z}-\rho g\right)^{2}\left(n_{j}^{4}-n_{j-1}^{4}\right),
\end{aligned}
$$

де параметри з індексом g є величинами на межах смуг. Враховуючи, як було вище обумовлено, що температура у смузі вважається незалежною від радіуса, перепишемо рівняння (10) у вигляді

$$
\begin{aligned}
& p c\left(Q_{j} \frac{d T_{j}}{d x}+R n_{j}\left(u_{g j} n_{j} \frac{d R}{d x}-v_{g j}\right)\left(T_{j}-T_{g j}\right)\right)-R n_{j-1}\left(u_{g j-1} n_{j-1} \frac{d R}{d x}-v_{g j-1}\right)\left(T_{j}-T_{g j-1}\right)= \\
& =R\left(n_{j} q_{j}-n_{j-1} q_{j-1}\right)+\frac{R^{4}}{16 \mu_{j}}\left(\frac{\partial p}{\partial z}-\rho g\right)^{2}\left(n_{j}^{4}-n_{j-1}^{4}\right) .
\end{aligned}
$$

Величини теплових потоків визначимо як $q_{j}=-2 \lambda_{j} \frac{T_{j}-T_{g j}}{R\left(n_{j}-n_{j-1}\right)}$. При цьому необхідно, щоб на межах смуг температури та теплові потоки були рівними, тому між середніми температурами у смугах і на межах виконуються прості співвідношення

$$
T_{g j}=\frac{\lambda_{j}}{\lambda_{j}+\lambda_{j+1}} T_{j} \frac{\lambda_{j+1}}{\lambda_{j}+\lambda_{j+1}} T_{j+1}, \quad q_{j}=-\frac{2}{R\left(n_{j}-n_{j-1}\right)} \frac{\lambda_{j} \lambda_{j+1}}{\lambda_{j}+\lambda_{j+1}}\left(T_{j}-T_{j+1}\right) .
$$




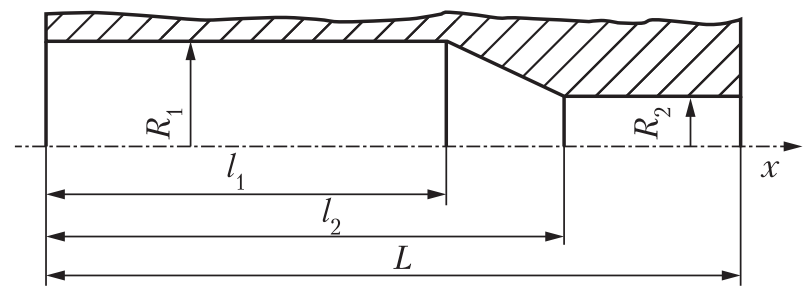

Puc. 1. Схема екструзійного каналу
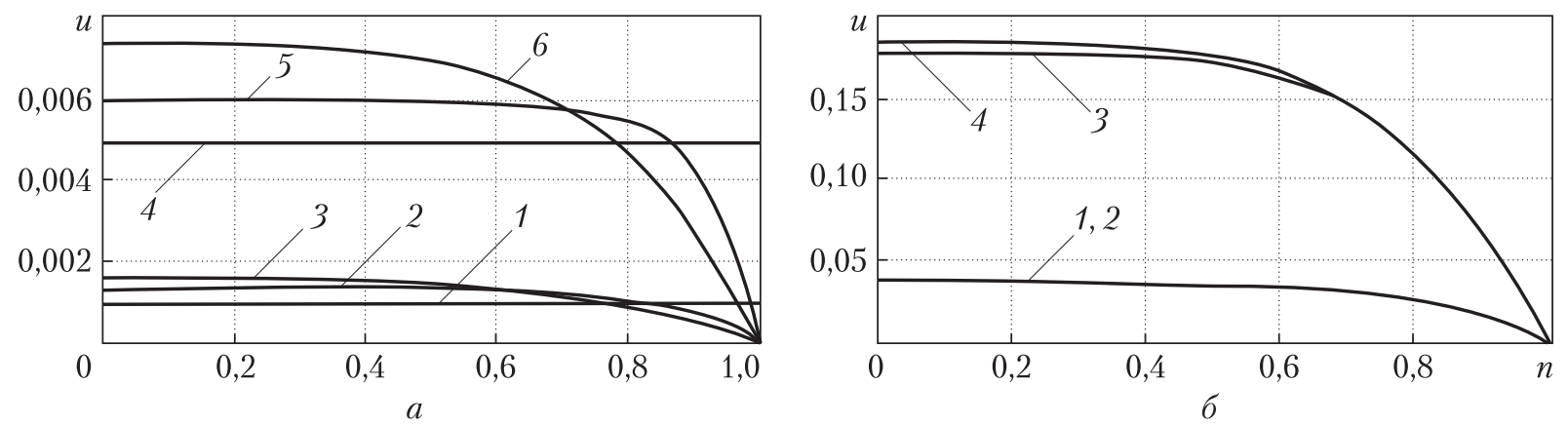

Puc. 2. Профілі поздовжніх швидкостей $u$ (м/с) у поперечних перерізах каналу екструдера: $a$ - широка частина каналу (криві 1 та $4-\zeta_{1}=0,002 ; 2$ та $5-\zeta_{2}=0,02 ; 3$ та $6-\zeta_{3}=0,85$ ); номери $1-3$ відносяться до першого варіанта $U_{\mathrm{C}}=0,001 \mathrm{~m} / \mathrm{c}, 4-6-$ до варіанта $3 U_{\mathrm{C}}=0,005 \mathrm{~m} / \mathrm{c} ; 6-$ насадок (криві 1 та $4-$ $\zeta_{4}=0,95 ; 2$ та $\left.3-\zeta_{5}=1\right)$. Номери 1 та 2 відносяться до варіанта з $U_{\mathrm{C}}=0,001 \mathrm{~m} / \mathrm{c}$, номери 3 та $4-$ до варіанта з $U_{\boldsymbol{C}}=0,005 \mathrm{M} / \mathrm{c}$

У запропонованому тут методі для уточнення в'язкості передбачається робити ітерації в межах одного кроку. Однак з малими кроками інтегрування збіжність методу без ітераційних наближень на кожному кроці повинна приводити до стійкого рахування з плавною зміною визначених параметрів, що і спостерігається в результатах. Отже, наведена постановка задачі дає порівняно простий і зручний метод розрахунку та встановлення якісних залежностей модельованих величин від геометричних розмірів екструзійного апарата та основних визначальних параметрів для дилатантних і псевдопластичних рідин.

Результати розрахунків. У розрахунках були прийняті такі величини (рис. 1): радіус широкої частини $R_{1}=0,001$ м; радіус вузької частини $R_{2}=0,0002$ м; довжина робочої частини $L=0,2$ м; довжина широкої циліндричної частини $l_{1}=0,17$ м; довжина каналу до вузької частини $l_{2}=0,19 \mathrm{~m} ; \zeta=\mathrm{x} / \mathrm{L}-$ відносна довжина каналу; $\rho=1080$ кг $/ \mathrm{m}^{3}$; початкова температура стрижня $T_{\mathrm{C}}=293 \mathrm{~K}$; температура плавлення $T_{\mathrm{P}}=510 \mathrm{~K}$; температура стінки $T_{\mathrm{W}}=512 \mathrm{~K} ; c=1500$ Дж/(кг $\left.\cdot \mathrm{K}\right) ;$ в’язкість $\mu=0,282\left(\frac{15}{1+2 \gamma}\right)^{0,75} \exp \left(\frac{5255,326}{T}\right)$ Па $\cdot \mathrm{c}$; $\lambda=0,2$ Дж/(м · c $\cdot$ K); полімери аморфні, прихованою теплотою фазових переходів нехтуємо.

Чисельні розв’язки показано на рис. 2, де представлено профілі поздовжніх швидкостей у різних перерізах екструдера для двох випадків подачі швидкостей $-U_{\mathrm{C}}=0,001 \mathrm{м} / \mathrm{c}$ та 0,005 м/с. У широкій частині екструдера (рис. 2, a) добре видно, як профілі швидкостей від стрижневого руху (криві 1 та 4) перебудовуються до стабілізованої течії в’язкої рідини. 

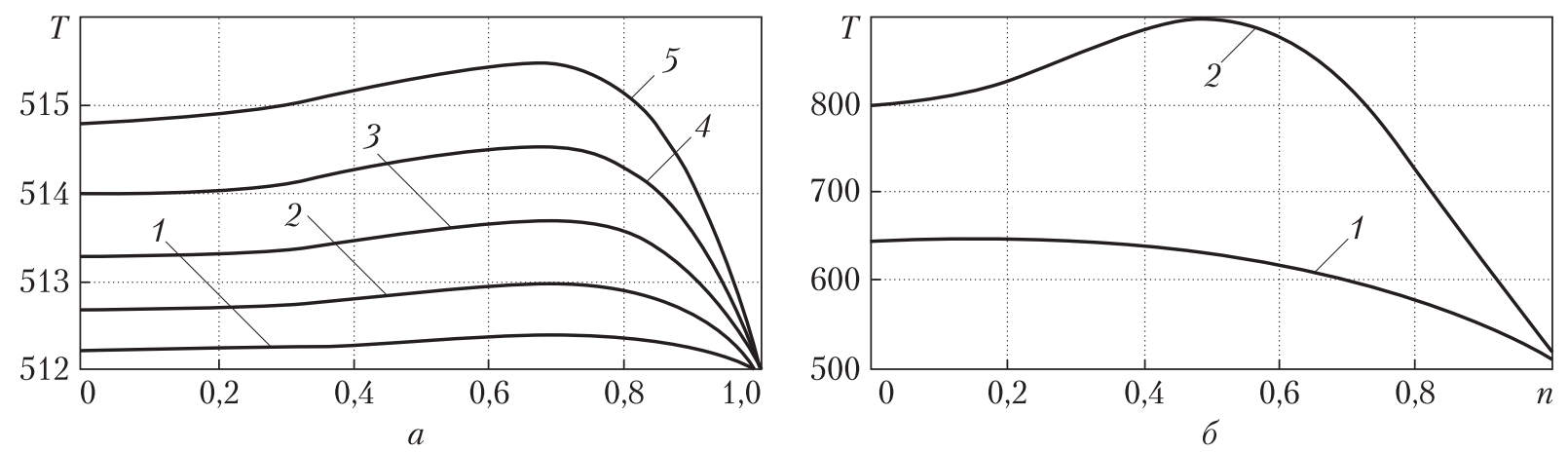

$\boldsymbol{P u c . 3 . ~ П р о ф і л і ~ т е м п е р а т у р ~ у ~ п е р е р і з і ~ н а ~ в и х о д і ~ з ~ а п а р а т а ~ ( ~} a$ ) и екструдера (б): $1-U_{\mathrm{C}}=0,001 \mathrm{~m} / \mathrm{c}, 2-0,002$ $\mathrm{M} / \mathrm{c}, 3-0,003 \mathrm{~m} / \mathrm{c}, 4-0,004 \mathrm{~m} / \mathrm{c}, 5-0,005 \mathrm{~m} / \mathrm{c}$

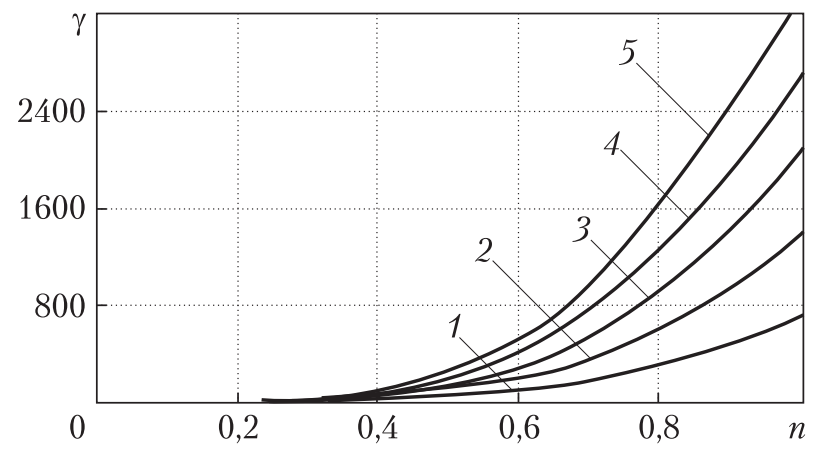

Puc. 4. Розподіл $\gamma$ у перерізі на виході з апарата: $1-U_{\mathrm{C}}=0,001 \mathrm{~m} / \mathrm{c}, 2-0,002 \mathrm{~m} / \mathrm{c}, 3-0,003 \mathrm{~m} / \mathrm{c}$, $4-0,004 \mathrm{~m} / \mathrm{c}, 5-0,005 \mathrm{~m} / \mathrm{c}$

У вузькому каналі (рис. 2, б) профілі практично не змінюються по довжині насадка. При цьому добре видно, що вони є більш наповненими, тобто відрізняються від параболічних профілів, характерних для ньютонівських рідин. Майже до $n=0,6$ швидкості слабко змінюються поперек каналу і тільки ближче до стінки вони зменшуються до нуля. На рис. 3, $a$ показано профілі температур у перерізі на виході з апарата. Це важлива характеристика, яка для тривимірного друку має велике значення. 3 рис. 3 випливає, що навіть для порівняно великої швидкості подачі матеріалу 0,005 м/с перевищення температури над температурою плавлення становить близько 5 град. Наведемо для порівняння криві температур у кінці апарата на зрізі сопла (рис. 3,6 ) в умовному матеріалі із залежністю в'язкості у вигляді (1), але з коефіцієнтом $a=0$. Це практично відповідатиме деякому ньютонівському матеріалу.

Цей рисунок свідчить про те, що для умовної ньютонівської рідини величини теплової енергії від дисипації є дуже великими. У псевдопластичних рідинах (див. рис. 3, $a$ ), за великих градієнтів швидкості в'язкість значно падає, що призводить до зменшення дисипації і відповідно до зменшення виділення теплової енергії.

На рис. 4 наведено криві градієнтів швидкості $\gamma$ для різних швидкостей подачі полімеру, з якого видно, що ці величини досягають великих значень, в результаті чого в'язкість і зменшується. У цьому полягає велика перевага псевдопластичних рідин, зокрема, пластиків типу АБС. Важливою особливістю процесу (див. рис. 3, $a$ ) є те, що температура внутрішніх 
шарів є трохи нижчою за температуру в шарах з $n=0,6 \div 0,8$. Це свідчить, що дисипація відбувається переважно в пристінкових шарах полімеру, в основному завдяки великим величинам $\gamma$. Частина цієї теплової енергії перекачується теплопровідністю всередину шару, а чимала частина йде в стінку каналу. В цілому практично вся маса полімеру навіть при швидкості подачі $U_{\mathrm{C}}=0,001 \mathrm{~m} /$ с перебуває в розплавленому стані, але з невеликим перегрівом. Величина $\gamma$, як це видно з результатів розрахунку, відіграє двояку роль. Її зростання має зумовлювати зростання дисипативного члена в рівнянні теплообміну, але з іншого боку 3 ростом градієнта швидкості значно, як у випадку розглянутого полімеру, падає його в’язкість, що і призводить до зменшення дисипації.

Псевдопластичні рідини цілком зручні для використання в процесі тривимірного друку, тому що в результаті великих поперечних градієнтів поздовжньої швидкості значно знижується в’язкість матеріалу, що призводить до зменшення теплової енергії, яка виділяється за рахунок дисипації механічної. Це, в свою чергу, перешкоджає великому перегріву матеріалу, що робить друкування більш стійким.

\section{ЦИТОВАНА ЛІТЕРАТУРА}

1. Астарита Дж., Марручи Дж. Основы гидромеханики неньютоновских жидкостей. Москва: Мир, 1978. $309 \mathrm{c}$.

2. Чанг Дей Хан Реология в процессах переработки полимеров. Москва: Химия, 1979. 366 с.

3. Теплофизические и реологические характеристики полимеров: Липатов Ю.С. (ред.). Киев: Наук. думка, 1977. 244 с.

4. Яхно О.М., Дубовицкий В.Ф. Основы реологии полимеров. Киев: Вища шк., 1976. 188 с.

5. Яхно О.М., Желяк В. І. Гідравліка неньютонівських рідин. Навч. посібник. Київ: Вища шк., 1995. 199 с.

6. Коваленко Р. В. Современные полимерные материалы и технологии 3D печати. КиберЛенинка. URL: https://cyberleninka.ru/article/n/sovremennye-polimernye-materialy-i-tehnologii-3d-pechati (дата звернення: 19.03.2021).

7. Экструзионные головки для пластмасс и резины: Конструкции и технические расчеты: Володин В.П. (ред.). СПб.: Профессия, 2007. 472 с.

8. Шкуро А.Е., Кривоногов П.С. Технологии и материалы 3D-печати. Уч. пособ. Екатеринбург: УГЛТУ, 2017. 101c.

9. Ким В.С. Теория и практика экструзии полимеров. Москва: Химия, КолосС, 2005. 284 с.

10. Ревяко М.М., Прокопчук Н.Р. Теоретические основы переработки полимеров. Минск: БГТУ, 2009. $305 \mathrm{c}$.

Надійшло до редакції 17.06.2021

\section{REFERENCES}

1. Astarita, Dzh. \& Marruchi, Dzh. (1978). Fundamentals of the hydromechanics of non-Newtonian fluids. Moscow: Mir (in Russian).

2. Chang, Dey Han (1979). Rheology in polymer processing. Moscow: Himiya (in Russian).

3. Lipatov, Yu. S. (Ed.). (1977). Thermophysical and rheological characteristics of polymers. Kiev: Naukova Dumka (in Russian).

4. Yahno, O. M. \& Dubovitskiy, V. F. (1976). Fundamentals of Polymer Rheology. Kiev: Vischa shkola (in Russian).

5. Yahno, O. M. \& Zhelyak, V. I. (1995). Hydraulics of non-Newtonian fluids. Educational manual. Kiev: Vischa shkola (in Ukrainian).

6. Kovalenko, R. V. Modern polymer materials and 3D printing technologies. CyberLeninka.

URL: https://cyberleninka.ru/article/n/sovremennye-polimernye-materialy-i-tehnologii-3d-pechati (in Russian). 
7. Volodin, V. P. (Ed.). (2007). Extrusion heads for plastics and rubber: Designs and technical calculations. $\mathrm{SPb} .:$ Professiya. (in Russian).

8. Shkuro, A. E. \& Krivonogov, P. S. (2017). Technologies and materials for 3D printing. Tutorial. Ekaterinburg: UGLTU (in Russian).

9. Kim, V. S. (2005). Theory and practice of polymer extrusion. Moscow: Himiya, KolosS (in Russian).

10. Revyako, M. M. \& Prokopchuk, N. R. (2009). Theoretical foundations of polymer processing. Minsk: BGTU (in Russian).

Received 17.06.2021

A.F. Bulat ${ }^{1}$, https://orcid.org/0000-0002-6541-2140

V.I. Yelisieiev ${ }^{1}$, https://orcid.org/0000-0003-4999-8142

Ye.V. Semenenko ${ }^{1}$, https://orcid.org/0000-0001-8707-3648

N.N. Stadnychuk ${ }^{1}$, https://orcid.org/0000-0002-2990-9635

B.A. Blyuss ${ }^{2}$, https://orcid.org/0000-0003-3077-1220

${ }^{1}$ M.S. Poljakov Institute of Geotechnical Mechanics of the NAS of Ukraine, Dnipro

${ }^{2}$ Prydniprovsky Research Center of the NAS of Ukraine and MES of Ukraine, Dnipro

E-mail: office.igtm@nas.gov.ua, VIYelisieiev@nas.gov.ua,evs_post@meta.ua, bblyuss@gmail.com

\section{NONNEWTONIAN FLUID FLOW IN AN EXTRUSION APPARATUS} FOR THREE-DIMENSIONAL PRINTING

Mathematical extrusion models show that, during the flow of highly viscous liquids in the process of threedimensional printing, there is a problem of working medium heating. It is that, during the material supply, the mechanism of dissipation of the mechanical energy into the heat is activated, which leads to the liquid overheating. In turn, this can lead to a resulting product shape mismatch. For a stable forming, it is necessary that the supplied material to be melted near the apparatus walls. Overheating should be minimal. So, while leaving the nozzle, the material can be hardened quickly, preferably without additional blowing devices. This article discusses the problem of the polymer mass movement in the heated channel in order to determine the necessary conditions for such operation, based on the definite extruder geometric shapes. As the model fluid, an inelastic medium with a viscosity depending on temperature and velocity gradients is used. Such class of nonnewtonian model fluids widely used in practical calculations serves to define parameters of the polymers flow and to predict certain products properties. Due to the minor properties manifestations or clear localization of the effects neglecting the polymers elastic properties is often justified. To solve the problem formulated in the framework of a narrow channel theory, the method of bands is used, when the temperature is assumed to be constant, i.e. independent of the transverse coordinate. This makes it possible to base the solution on known analytical expressions for velocities with their subsequent clarification, due to the complex dependence of the viscosity on velocity gradients. By refining the flow dynamic parameters from the previous step at each step, it is possible to obtain numerically quite stable smooth solutions. Calculations were performed for a nonnewtonian fluid similar in properties to the polymer ABS-3A. Calculations show that the pseudoplasticity characteristic, inherent in this polymer, plays an important role in the extrusion process. Due to the fact that, with longitudinal velocity transverse gradient increasing, the polymer viscosity decreases significantly, the mechanical energy dissipation amount also decreases, i.e. the thermal energy released during the dissipation decreases. This, in turn, leads to a less heating of the moving polymeric material. Therefore, based on the apparatus geometric dimensions, it is possible to simulate the polymer liquid flow and to select the liquid formation and temperature parameters at the apparatus outlet.

Keywords: nonnewtonian fluids, polymers, viscosity, temperature, extrusion apparatus. 